\title{
A comparison of intraocular pressure values obtained using a Goldmann applanation tonometer and a handheld version of applanation resonance tonometer: A preliminary report
}

\author{
Małgorzata Mulak ${ }^{A-F}$, Wojciech A. Czak ${ }^{A-D}$, Małgorzata Mimier ${ }^{D, E}$, Radosław Kaczmarek ${ }^{C, E}$ \\ Department and Clinic of Ophthalmology, Wroclaw Medical University, Poland \\ A - research concept and design; $\mathrm{B}$ - collection and/or assembly of data; $\mathrm{C}$ - data analysis and interpretation; \\ $D$ - writing the article; $E$ - critical revision of the article; $F$ - final approval of the article
}

Address for correspondence

Małgorzata Mulak

E-mail: xbangera@tlen.pl

Funding sources

None declared

Conflict of interest

None declared

Received on August 25, 2016

Reviewed on October 2, 2016

Accepted on January 18,2017

\begin{abstract}
Background. Despite the development of various methods of intraocular pressure (IOP) measurement, Goldmann applanation tonometry (GAT) is still the most popular. The measurement using GAT depends on the biomechanical properties of the cornea, such as the thickness, the radius of curvature, as well as the amount of the fluorescein used.
\end{abstract}

Objectives. The aim of the study was to compare IOP values measured by GAT with those measured by applanation resonance tonometry (ART).

Material and methods. A total of 47 patients (94 eyes), including 28 patients with primary open-angle glaucoma (POAG) and 19 subjects from the control group, were examined at the Glaucoma Outpatient Clinic of the Department and Clinic of Ophthalmology at Wroclaw Medical University (Poland). The measurements of IOP were performed using GAT and a handheld version of ART. Also, the central corneal thickness (CCT) of all patients was measured.

Results. The study showed that the IOP values measured by both tonometers were comparable, but ARTacquired values were higher than GAT-obtained values both in the glaucomatous group and in the control group. CCT had little impact on mean IOP difference between GAT- and ART-obtained values.

Conclusions. Applanation resonance tonometry is a precise method of IOP measurement and is less affected by biomechanical properties of the cornea than GAT. Our results show that ART is a new, promising, comfortable for both patients and doctors method of IOP measurement, which, in the future, can replace GAT. Key words: comparison, glaucoma, applanation resonance tonometry, Goldman applanation tonometry

DOI

10.17219/acem/68559

Copyright

Copyright by Author(s)

This is an article distributed under the terms of the

Creative Commons Attribution Non-Commercial License

(http://creativecommons.org/licenses/by-nc-nd/4.0/) 


\section{Introduction}

Goldmann applanation tonometry (GAT), despite over 50 years of history, is still considered the gold standard for intraocular pressure (IOP) measurement and is recommended by the European Glaucoma Society (EGS) as the most precise method. ${ }^{1}$ Invented by Hans Goldmann in 1957, this technique is based on the Imbert-Fick law, in which the force required to flatten the sphere is a measure of IOP. The rule assumes that the surface of the sphere is perfectly dry and smooth. ${ }^{2}$ Furthermore, the measurement depends on the biomechanical properties of the cornea, including the thickness, the radius of curvature, as well as the amount of the fluorescein used. Goldmann applanation tonometry is a tonometer calibrated to the mean corneal thickness $520 \mathrm{~nm}$, thus, it is not accurate for every type of the cornea. ${ }^{3}$

The studies show that the values of IOP measured by GAT are underestimated in patients after refractive eye surgery, and the number of those patients is still increasing. It was proven that ablation of the center of the cornea results in a constant decrease of IOP values by approx. $1.6 \mathrm{~mm} \mathrm{Hg}$ in myopic eyes, as well as in hyperopic eyes. Additionally, extra reduction of IOP was observed in myopic patients $(0.029 \pm 0.003 \mathrm{~mm} \mathrm{Hg}$ per $1 \mu \mathrm{m}$ of excised tissue), which is explained by the fact that the location of maximum ablation is in the center of the cornea. Assuming that $15 \mu \mathrm{m}$ of tissue is excised for correction of 1 diopter, every corrected diopter decreases IOP by $0.5 \mathrm{~mm} \mathrm{Hg}$. The study confirms that GAT can show incorrect values of IOP after refractive surgery and in patients with corneal disorders. ${ }^{4}$ Changes in the structure of the eye or the orbital cavity, various amount of fluorescein, astigmatism, eye clenching, as well as too narrow collar or tie, can also impact IOP measurement. ${ }^{1}$

Applanation resonance tonometry (ART) is one of the new methods of IOP measurement. Although the contact with the cornea resembles the Goldmann tonometer, the mechanism of measurement has changed. A convex, bakelite tip equipped with piezoelectric resonator is intended to measure the resonance frequency. That mechanism enables the simultaneous measurement of the applanation and the force required to applanate the cornea. Two versions of that tonometer are available - automatic (servo-controlled) and manual. It can be attached to a slit lamp, which is similar to GAT, or handheld. Applanation resonance tonometry has been known for many years and was described as a new, promising method. The correlation between GAT- and ART-acquired readings was analyzed in many studies. ${ }^{5-7}$

ART, as well as GAT, can be performed with the use of a slit lamp; it depends on the flattening of the desensitized cornea by an automatically exsertile tip. Three measurements of IOP are made, then averaged, but the contact time with the cornea is much shorter than during GAT, which greatly reduces the risk of cornea damage. There is no need to use fluorescein. ${ }^{7,8}$

\section{Objectives}

The aim of the study was to compare IOP values measured by GAT with those measured by ART. The handheld version of an automatic ART was used in this study.

\section{Material and methods}

Ninety-six eyes of 48 patients were enrolled in the study. Two eyes of 1 patient were excluded due to measurement failure. Finally, the study included 94 eyes of 47 patients - 56 eyes of 28 patients with primary open-angle glaucoma (POAG) treated pharmacologically, and 38 eyes of 19 healthy patients in the control group. The mean age of the patients was 59 years (range 23-83). The study included 64 female eyes and 30 male eyes. Pseudophakic patients after at least 6 months after cataract surgery were also qualified for the study. The Goldmann applanation tonometry results were corrected by CCT value $\left(\mathrm{GAT}_{\mathrm{CCT}}\right)$, Goldmann applanation tonometry results without corrections by CCT value $\left(\mathrm{GAT}_{\text {noCCT }}\right)$ and applanation resonance tonometry results (ART) were compared. The measurements were made with at least a 10-min gap after each test, and the tests were performed in a random order. Central corneal thickness was measured by an ultrasound corneal pachymeter PIROP (ECHO-SON S.A., Puławy, Poland).

Statistical analysis was performed using STATISTICA v. 12 software. Distribution of the results was checked using the Shapiro-Wilk normality test. Differences and variance between GAT and ART were assessed using linear regression. The p-value $<0.05$ was considered statistically significant. Correlation analysis was performed using Pearson correlation coefficient.

\section{Results}

Mean GAT $_{\text {CCT }}$ was $16.46 \mathrm{~mm} \mathrm{Hg}$, while mean GAT $_{\text {noCCT }}$ was $17.27 \mathrm{~mm} \mathrm{Hg}$. Mean IOP measured with ART was $17.72 \mathrm{~mm} \mathrm{Hg}$ (Table 1). The mean absolute value of IOP difference $\left|\left(\mathrm{ART}-\mathrm{GAT}_{\mathrm{CCT}}\right)\right|$ was $1.87 \mathrm{~mm} \mathrm{Hg}$ with SD of $1.24 \mathrm{~mm} \mathrm{Hg}$. When compared to other differences, the calculated value was low with the lowest variance. The mean IOP difference (ART - GAT $\mathrm{CCT}_{\text {T }}$ ) was $1.40 \mathrm{~mm} \mathrm{Hg}$ with SD of $1.76 \mathrm{~mm} \mathrm{Hg}$. The mean absolute value of IOP difference (ART - GAT noCCT ) was $2.07 \mathrm{~mm} \mathrm{Hg}$ with SD of $1.70 \mathrm{~mm} \mathrm{Hg}$. The mean IOP difference (ART $\mathrm{GAT}_{\text {noCCT }}$ ) was $0.48 \mathrm{~mm} \mathrm{Hg}$, however, with a comparably higher SD of $2.64 \mathrm{~mm} \mathrm{Hg}$ (Table 2).

Intracular pressure, measured by both ART and GAT, was higher in the glaucoma group than in the control group $(\mathrm{p}<0.05)$. A statistical analysis showed the most significant correlation between the ART values and the $\mathrm{GAT}_{\mathrm{CCT}}$ values (correlation test $\mathrm{p}<0.05$, correlation coefficient $=0.66$ ). When compared to GAT, ART overstated IOP by about $2 \mathrm{~mm} \mathrm{Hg}$. 
Table 1. Mean values for ART, GAT deviation (SD) in $\mathrm{mm} \mathrm{Hg}$

\begin{tabular}{|l|c|c|}
\hline \multicolumn{1}{|c|}{ Method } & Mean value $[\mathrm{mm} \mathrm{Hg}]$ & SD $[\mathrm{mm} \mathrm{Hg}]$ \\
\hline ART & 17.72 & 3.36 \\
\hline GAT $_{\text {CCT }}$ & 16.46 & 3.39 \\
\hline GAT $_{\text {noCCT }}$ & 17.27 & 3.48 \\
\hline
\end{tabular}

Table 2. Mean differences between IOP measurements with standard deviation (SD)

\begin{tabular}{|l|c|c|}
\multicolumn{1}{|c|}{ Mean difference } & $\begin{array}{c}\text { value } \\
{[\mathrm{mm} \mathrm{Hg}]}\end{array}$ & $\begin{array}{c}\text { SD } \\
{[\mathrm{mm} \mathrm{Hg}]}\end{array}$ \\
\hline ART - GAT & 1.4 & 1.76 \\
\hline |ART - GAT $_{\text {CCT }}$ (absolute values) & 1.87 & 1.24 \\
\hline ART - GAT & 0.48 & 2.64 \\
\hline nocCT & 2.07 & 1.70 \\
\hline
\end{tabular}

The mean IOP difference between $\mathrm{ART}$ and $\mathrm{GAT}_{\mathrm{CCT}}$ was $2.12 \pm 1.49 \mathrm{~mm} \mathrm{Hg}$ (values > $12 \mathrm{~mm} \mathrm{Hg}$ ); $1.83 \pm 1.18 \mathrm{~mm} \mathrm{Hg}$ (in the range of $12-18 \mathrm{~mm} \mathrm{Hg}$ ); and $1.75 \pm 1.15 \mathrm{~mm} \mathrm{Hg}$ (values $>18 \mathrm{~mm} \mathrm{Hg}$ ). According to ISO criteria for new tonometers, only in $5 \%$ of measurements the difference may be higher than $5 \mathrm{~mm} \mathrm{Hg}$. Tables 3 and 4 show the percentage of measurement values in which the differences between ART and $\mathrm{GAT}_{\text {noCCT }}$, and between ART and $\mathrm{GAT}_{\mathrm{CCT}}$ exceeded $\pm 5 \mathrm{~mm} \mathrm{Hg}$. Unlike in the previous study with ART attached to a slit lamp, overstated high IOP values in manual ART were not noticed. ${ }^{9}$ Corneal thickness had a little impact on the mean ART and GAT difference in IOP. The attempt to correct ART values by CCT reduces the correlation between ART and GAT.

\section{Discussion}

Our study proved that IOP values measured by ART and GAT were comparable. Nonetheless, ART tends to overstate the higher values of the pressure. The correlation between a Goldmann tonometer and a resonance tonometer is more significant when using a handheld, automatic version in comparison with ART attached to a slit lamp.

One of the first studies that compared GAT and ART was conducted by Hallberg et al. on 24 healthy patients and $24 \mathrm{pa}-$ tients with elevated IOP. ${ }^{6}$ Intracular pressure was measured with the use of ART, during the corneal indentation phase and the phase when the sensor was removed. Goldmann tonometry was used as a reference method. The study showed a significant correlation between IOP indentation and IOP GAT $(\mathrm{R}=0.92 ; \mathrm{p}<0.001 ; \mathrm{SD}=3.6 \mathrm{~mm} \mathrm{Hg}$; $\mathrm{n}=104)$, as well as between IOP removal and IOP GAT $(\mathrm{R}=0.94 ; \mathrm{p}<0.001 ; \mathrm{SD}=3.1 \mathrm{~mm} \mathrm{Hg}, \mathrm{n}=104)$.

In further studies on a porcine eye model evaluating the use of ART for IOP measurement, ART-acquired values

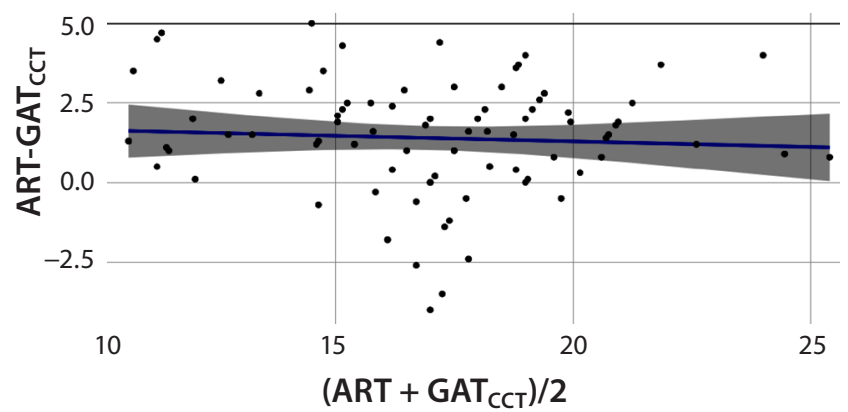

Fig. 1. The difference between Goldmann Applanation Tonometry corrected by CCT (GAT $C$ CT $)$ and ART as a function of their mean IOP ( $n=94$ eyes). Solid lines show $\pm 5 \mathrm{~mm} \mathrm{Hg}$. Correlation coefficient $=0.38$. Correlation test $\mathrm{p}$-value $=0.0001$

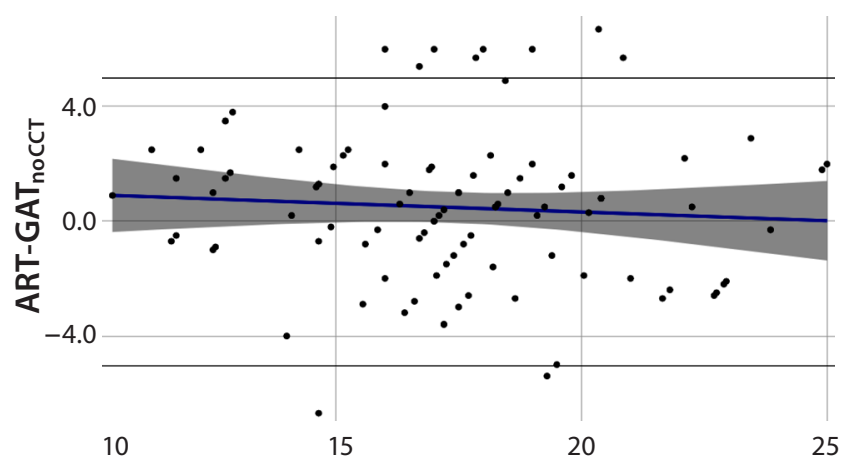

$(\mathrm{ART}+\mathrm{GAT}$ noccT $) / 2$

Fig. 2. The difference between Goldmann Applanation Tonometry (GAT $T_{\text {nocct }}$ ) and ART. As a function of their mean IOP ( $n=94$ eyes) Solid lines show $+/-5 \mathrm{~mm} \mathrm{Hg}$. Correlation coefficient $=0.09$, with correlation test $\mathrm{p}=0.38$

Table 3. Number and percentage of measurements in which the difference between ART and GAT nocct was higher than $5 \mathrm{~mm} \mathrm{Hg}$ (according to ISO standards for new tonometers)

\begin{tabular}{|l|c|c|}
\multicolumn{1}{|c|}{ IOP mm Hg } & ART $-\mathrm{GAT}_{\text {nосC }}>5 \mathrm{~mm} \mathrm{Hg}$ & $\%(\mathrm{n}>5 \mathrm{~mm} \mathrm{Hg}) /(\mathrm{n})$ \\
\hline $9-16 \mathrm{~mm} \mathrm{Hg}(\mathrm{n}=39)$ & $\mathrm{n}=6$ & 15.39 \\
$>16 \mathrm{~mm} \mathrm{Hg} ;<23 \mathrm{~mm} \mathrm{Hg}(\mathrm{n}=47)$ & $n=7$ & 14.8 \\
\hline $23 \mathrm{~mm} \mathrm{Hg}(\mathrm{n}=8)$ & $n=0$ & 0 \\
\hline Total $(n=94)$ & $n=13$ & 13.8 \\
\hline
\end{tabular}

Table 4. Number and percentage of measurements in which the difference between ART and GAT CCT was higher than $5 \mathrm{~mm} \mathrm{Hg}$ (according to ISO standards for new tonometers)

\begin{tabular}{|l|c|c|}
\multicolumn{1}{|c|}{ IOP mm Hg } & ART $-\mathrm{GAT}_{\mathrm{CCT}}>5 \mathrm{~mm} \mathrm{Hg}$ & $\%(\mathrm{n}>5 \mathrm{~mm} \mathrm{Hg}) /(\mathrm{n})$ \\
\hline $9-16 \mathrm{~mm} \mathrm{Hg}(\mathrm{n}=37)$ & $\mathrm{n}=0$ & 0 \\
$>16 \mathrm{~mm} \mathrm{Hg} ;<23 \mathrm{~mm} \mathrm{Hg}(\mathrm{n}=55)$ & $n=0$ & 0 \\
$\geq 23 \mathrm{~mm} \mathrm{Hg}(\mathrm{n}=2)$ & $n=0$ & 0 \\
\hline Total $(n=94)$ & $n=0$ & 0 \\
\hline
\end{tabular}


were thought to be strongly operator-dependent. ${ }^{10}$ However, more detailed studies regarding this topic showed that operator dependency did not significantly affect IOP values. The research by Hallberg et al. proved that offcenter placement of the new designed device with a larger contact surface $(7 \mathrm{~mm})$ is not clinically significant. The precision of ART was well within the ISO standard requirements for a tonometer. ${ }^{11}$ Precision of the 2 versions of ART - handheld and biomicroscope - was analyzed in a large, randomized, prospective study performed on 153 human eyes. The study presented that both ART attached to a slit lamp and handheld ART met the ISO criteria for tonometers. The biomicroscope setup demonstrated a marginally better precision when compared with handheld ART. ${ }^{12}$

The aim of the study by Jóhannesson et al. was to define the correlation between servo-controlled ART and manual ART with regard to GAT. Seventy-seven patients (152 eyes) were examined by 6 measurements using each method. Intracular pressure during the indentation phase (the dynamic state) and IOP during 2-second applanation (the static state) were analyzed. The study showed that manual ART met the ISO criteria of the standard deviation range for both phases, while the servo-controlled ART fulfilled the criteria only during the static stage. ${ }^{7}$

Elevated intraocular pressure is the main risk factor of glaucoma development; therefore, the majority of studies are focused on this group of patients. Ottobelli et al. examined 115 glaucomatous patients and 63 patients from the control group. Goldmann tonometry and double resonance tonometry were performed in a random order. The statistical analysis showed that ART overestimated IOP on average by $1.3-1.7 \mathrm{~mm}$ Hg compared to GAT, especially in patients with high IOP. The ART results were repeatable but the $2^{\text {nd }}$ (ART 2 ) was lower than the $1^{\text {st }}(A R T 1)$, probably due to the increased tranquility of the patients during the $2^{\text {nd }}$ test. ${ }^{8,12}$ Also, Salvetat et al. investigated the repeatability and accuracy of servo-controlled ART. They obtained high repeatability of ART, but significantly lower than GAT. Common conclusion was drawn - ART overestimated GAT values, especially in patients with high IOP. ${ }^{8,13}$

Many papers compare new techniques of IOP measurement usually with a Goldmann tonometer as a reference point. Jóhannesson et al. in a prospective study of 53 subjects compared 3 tonometry methods - GAT, Pascal dynamic contour tonometry (DCT), and ART. The assessment of IOP was made prior to, directly after, 3 , and 6 months after laser-assisted sub-epithelial keratectomy (LASEK), which is known to have a great impact on biomechanical properties of the cornea. Six measurements were obtained with a 5-min gap after each test in a randomly selected eye. The reduction of IOP was observed in the $3^{\text {rd }}$ and $6^{\text {th }}$ month after the laser eye surgery; however, the biggest decrease of IOP was noticed in the GAT group after 6 months $(-1.7 \pm 1.8 \mathrm{~mm} \mathrm{Hg})$, then in the static
ART group $(-1.2 \pm 1.5 \mathrm{~mm} \mathrm{Hg})$, followed by DCT patients $(-1.1 \pm 1.6 \mathrm{~mm} \mathrm{Hg})$ and the dynamic ART group $(-1.0 \pm 1.5 \mathrm{~mm} \mathrm{Hg}) .{ }^{14}$ After 2 years of follow-up, dynamic ART showed no significant difference in the measured IOP. We concluded that corneal properties had the least impact on dynamic ART measurements, so we recommend it in patients after LASEK. ${ }^{15}$

Jóhannesson et al. analyzed the impact of ageing on eye proprieties in 2 healthy but age-differentiated groups. Intracular pressure was measured by ocular response analyzer (ORA), dynamic contour tonometry (DCT), applanation resonance tonometry (ART), and Goldmann applanation tonometry (GAT). Values obtained by ORA, DCT and GAT were higher in elderly patients than in the young population. Applanation resonance tonometry showed no difference of IOP between those groups. The authors suggest that age-independent results may be partially explained by the character of the ART method. The study also proved that ART does not depend on central corneal thickness (CCT) and corneal curvature (CC) ${ }^{16}$

Probable fluctuation of IOP after corneal surgeries was examined by Beckman et al. in a study from 2014. His research on 28 patients (29 eyes) after corneal crosslinking (CXL) and on a corresponding control group showed that ART can be a useful method for assessing corneal hysteresis $(\mathrm{CH}) .{ }^{17}$

In a recent study investigating the impact of multiple IOP measurements and the use of topical anesthetics on IOP, using GAT and ART, Jóhannesson et al. demonstrated the IOP reduction after repeated pressure measurements. Also, a reduction in IOP was observed after the use of topical anesthetics without multiple IOP measurements. Authors advise to take into account the reduction of IOP when topical anesthetics or repeated IOP measurements would be performed in a study. ${ }^{18}$

\section{Conclusion}

Applanation resonance tonometry, when compared to GAT, overstates IOP values by approx. $2 \mathrm{~mm} \mathrm{Hg}$. The difference between IOP measurements using ART and GAT is not significant in the range of tested values (8$25 \mathrm{~mm} \mathrm{Hg}$ ). The IOP level variance is comparable, which supports the statement that handheld ART is an equally predictable method as GAT. Its automatic, triple measurement along with the exam-quality indicator make ART a more objective method than GAT. Further technological improvement and large multi-center studies may improve ART position in the field of IOP tonometers.

\section{References}

1. Terminology and Guidelines for Glaucoma. $4^{\text {th }}$ ed. Savona, Italy: European Glaucoma Society; 2014.

2. Goldmann H, Schmidt T. Applanation tonometry. (in German) Ophthalmologica. 1957;134(4):221-242. 
3. Clement $\mathrm{Cl}$, Parker DG, Goldberg I. Intraocular pressure measurement in a patient with a thin, thick or abnormal cornea. Open Ophthalmol J. 2016;10:35-43.

4. Cacho I, Sanchez-Naves J, Batres L, Pintor J, Carracedo G. Comparison of intraocular pressure before and after laser in situ keratomileusis refractive surgery measured with Perkins tonometry, noncontact tonometry and transpalpebral tonometry. J Ophthalmol. 2015;2015:683895.

5. Eklund A, Hallberg $P$, Lindén $C$, Lindahl OA. An applanation resonator sensor for measuring intraocular pressure using combined continuous force and area measurement. Invest Ophthalmol Vis Sci. 2003;44(7):3017-3024.

6. Hallberg P, Lindén C, Lindahl OA, Bäcklund T, Eklund A. Applanation resonance tonometry for intraocular pressure in humans. Physiol Meas. 2004;25(4):1053-1065.

7. Jóhannesson G, Hallberg P, Eklund A, Lindén C. Introduction and clinical evaluation of servo-controlled applanation resonance tonometry. Acta Ophthalmol. 2012;90(7):677-682.

8. Ottobelli L, Fogagnolo P, Frezzotti P, et al. Repeatability and reproducibility of applanation resonance tonometry: A cross-sectional study. BMC Ophthalmol. 2015;15:36.

9. Mulak M, Czak W, Grobarek B, Borwińska M, Misiuk-Hojło M. Intraocular pressure measurements obtained using Goldmann applanation tonometry (GAT) and applanation resonance tonometry (ART) a comparison. Magazyn Lekarza Okulisty. 2015;9(3):140-145.

10. Hallberg $P$, Santala K, Lindén $C$, Lindahl OA, Eklund A. Comparison of Goldmann applanation and applanation resonance tonometry in a biomicroscope-based in vitro porcine eye model. J Med Eng Technol. 2006;30(6):345-352.

11. Hallberg $P$, Lindén $C$, Bäcklund T, Eklund A. Symmetric sensor for applanation resonance tomometry of the eye. Med Biol Eng Comput. 2006;44(1-2):54-60.

12. Hallberg $P$, Eklund $A$, Bäcklund $T$, Lindén $C$. Clinical evaluation of applanation resonance tonometry: A comparison with Goldmann applanation tonometry. J Glaucoma. 2007;16(1):88-93.

13. Salvetat ML, Zeppieri M, Tosoni C, Brusini P. Repeatability and accuracy of applanation resonance tonometry in healthy subjects and patients with glaucoma. Acta Ophthalmol. 2014;92(1):66-73.

14. Jóhannesson G, Hallberg P, Eklund A, Koskela T, Lindén C. Change in intraocular pressure measurement after myopic LASEK: A study evaluating Goldmann, Pascal and applanation resonance tonometry. J Glaucoma. 2012;21(4):255-259.

15. Jóhannesson G, Hallberg P, Eklund A, Koskela T, Lindén C. Change in intraocular pressure measurement 2 years after myopic laserassisted subepithelial keratectomy. J Cataract Refract Surg. 2012;38(9):1637-1642.

16. Jóhannesson G, Hallberg P, Ambarki K, Eklund A, Lindén C. Agedependency of ocular parameters: A cross-sectional study of young and elderly healthy subjects. Graefes Arch Clin Exp Ophthalmol. 2015;253(11):1979-1983.

17. Beckman RJ, Behndig A, Hallberg P, Linden C. Increased corneal hys teresis after corneal collage cross linking: A study based on applanation resonance technology. JAMA Ophthalmol. 2014;132(12):1426-1432.

18. Jóhannesson G, Hallberg P, Eklund A, Behndig A, Lindén C. Effects of topical anaesthetics and repeated tonometry on intraocular pressure. Acta Ophthalmol. 2014;92(2):111-115. 